\title{
25 Research Soure \\ Translation, Adaptation and Validation of the Middle East Lower Limb Score (MELLS) Into Arabic
}

\section{Sager Hanna}

Kuwait Ministry of Health

\section{Fahad AlKhalaf}

Kuwait Ministry of Health

\section{Awdhah AlSamhan}

Kuwait Ministry of Health

Hend AlHamdan

King Faisal Specialist Hospital and Research Center

\section{Bader AlAdwani}

Kuwait Ministry of Health

Aliaa Khaja ( $\nabla$ aliaa.khaja@gmail.com )

Ministry of Health https://orcid.org/0000-0001-5646-4857

\section{Research article}

Keywords: Joint pain, patient reported outcomes, knee, hip, surgery

Posted Date: August 6th, 2020

DOl: https://doi.org/10.21203/rs.3.rs-48841/v1

License: (c) (1) This work is licensed under a Creative Commons Attribution 4.0 International License. Read Full License

Version of Record: A version of this preprint was published at International Journal of Innovative Research in Medical Science on November 1st, 2020. See the published version at https://doi.org/10.23958/ijirms/vol05-i11/984. 


\section{Abstract}

Background: The Middle East Lower Limb Score (MELLS) is an adaptation of the WOMAC questionnaire, specifically adjusted according to the cultural issues of the middle eastern patients with Knee or hip disabilities. The primary objective of this study was to verify if the translation and adaptation of the MELLS into Arabic could be used with ease and consistency by Arab-speaking patients suffering lower limb disabilities.

Methods: 110 participants were involved in this study. We performed the internal consistency tests with Cronbach's alpha. We also calculated floor effects, ceiling effects, as well as test-retest reliability (intracorrelation coefficient). To estimate the validity of MELLS, we used two validated questionnaires WOMAC and OHS. We confirmed the validity of MELLS questionnaire using Spearman's correlation.

Results: MELLS had a Cronbach's alpha of 0.88 in the first assessment and 0.92 in the second assessment, which was very high and reliable. Both subscales of MELLS had an internal consistency higher than 0.85. No relevant ceiling and floor effect were observed among the responses. Furthermore, strong significant correlation with WOMAC subscales and OHS was observed, which suggested a good construct validity. Responsiveness of MELLS, however, proved to be lower (but not considerably) than other two questionnaires.

Conclusion: The Arabic Middle East Lower Limb Score (MELLS) is a useful and reliable diagnostic tool for Middle eastern patients with knee and hip problems.

\section{Background}

The Middle East Lower Limb Score (MELLS) is an adaptation of the WOMAC questionnaire, specifically adjusted according to the cultural issues of the middle eastern patients with Knee or hip disabilities. The Middle East Lower Limb Score is designed to test pain and functional outcomes for patients with cultural influences such as praying five times daily (kneeling and bending), squatting when toileting, sitting on the floor, and sitting cross-legged.

We made up the Middle East Lower Limb Score to determine which surgeries work and how to avoid giving patients unnecessary anterior knee pain or positional hip pain.

MELLS is derived from the WOMAC questionnaire. WOMAC is an acronym for the Western Ontario and McMaster Universities Osteoarthritis Index. It is a measure of physical disability and symptoms developed originally for osteoarthritis patients [1,2]. WOMAC was developed to evaluate clinically relevant changes in patient's health status due to treatment intervention [3]. More than a decade ago, Bellamy and colleagues provided proof of the reliability, responsiveness, and validity of the WOMAC in osteoarthritis patients undergoing hip or total knee arthroplasty, and in osteoarthritis patients treated with nonsteroidal anti-inflammatory drugs [1, 2]. But then, creating the measurement properties of any instrument within any group of patients is a continuous process [3]. Several studies reporting the 
responsiveness, validity, and reliability of the WOMAC have been carried out since these initial studies [4]. Also, the WOMAC has served as an outcome measure for the evaluation of the efficacy of other therapeutic interventions (such as acupuncture), and in groups of patients other than osteoarthritis of the knee and hip [5-7].

This study aims to prove the reliability and validity of the MELLS, as a PRO score to be used by clinicians in for evaluating Arabic speaking patients. The WOMAC and OHS were used for comparison in this study, as they have been translated into Arabic and cross-culturally adapted in the literature.

\section{Methods}

\section{Participants}

A pilot study was conducted on 10 patients initially ( 5 with hip problem and 5 with knee problems), in clinic chosen at random to fill out the questionnaire. Then the patients were asked about their interpretation of each item, language ease, understanding of the concepts and assessed for need of assistance when filling out the questionnaire before launching the full-scale study.

The data was gathered randomly from 110 patients who had undergone a surgical intervention for their knee or hip. The subjects completed the MELLS questionnaire. They gave their written consent to use the information they had provided for the purpose of this study. The average age of the participants was 48.1 years, with standard deviation of 15.07 years; implying that the majority of the sample was between 33 and 63 years of age. The youngest participant was 18, and the oldest was 78 years of age. The female to male ratio 1:1. The patients were given 3 patient related outcome questionnaires adapted for Arabic speakers, including MELLS, WOMAC and OHS.

\section{Questionnaires}

\section{The Middle East Lower Limb Score (MELLS)}

This questionnaire consists of 43 questions, all of which are focused on the problems patients are experiencing with their lower limbs (knee and hip). This questionnaire is primarily an adaptation of WOMAC questionnaire, which is adjusted to specifically address the cultural issues of the middle eastern patients. MELLS uses five point Likert-type scale, where 0 indicates that the respondent is not experiencing any difficulties/pain, and 5 indicates that the patient experiences the highest level of difficulty/pain. Unlike WOMAC, this questionnaire consists of two domains, Pain (25 Items) and Daily activity (18 Items). One score is calculated for each patient by summing the responses to all of the 43 items. Therefore, a score of 172 means that the patient is experiencing severe hip/knee difficulty/pain. In order to standrdize the scores with 0-100 metric system, the following formula is used:

100

Maximum Possible Domain Score

$\times$ Actual Score 
All 110 patients have completed MELLS-questionnaire in at least two different occasions after the surgical intervention (T1 and T2). There was a 2 week interval between the first two times they had filled the questionnairs [4-5].

\section{Western Ontario and McMaster Universities Osteoarthritis Index (WOMAC)}

Arabic version of WOMAC has been already validated in the study conducted by Guermazi M. et al., thus, it was used in this study to investigate the validity of MELLS [8]. There were 24 Likert-type questions here and each patient had scores from three different subscales. First subscale - pain - had 5 questions (score range 5-20), 2 questions addressed stiffness (score range 2-8), and physical function had 17 questions (range 17-68). A minimum score on each of the subscales means that patient essentially did not feel any discomfort in his/her hip (if any), and a higher score suggests greater disability. At the end, the WOMAC scores were rescaled according to 0-100 system. The survey was taken in two different occasions, with a time period of 2 weeks between them.

\section{Oxford - 12 Item Hip Score}

Another questionnaire which was used in this study to investigate the validity of MELLS was Oxford Hip Score (OHS). Arabic version of OHS has already been validated by Khaja A. et al. and could be used to examine the validity of MELLS [9]. This questionnaire consists of 12 questions, all of which are focused on the patients' hip problems. To answer these questions, repondents use five point Likert-type scale, where 1 indicates that the respondent is not experiencing any difficulties, while 5 indicates that the patient experiences the highest level of difficulty. One score is calculated for each patient by summing the responses to all of the 12 items. Therefore, a score of 60 means that the patient is experiencing severe hip pain.

\section{Patient Burden and feasibility}

We recorded the average time it took each participant to fill out the questionnaire as well as if they required any assistance during the process as part of the patient-burden investigation. The feasibility was determined. It took an average of 6 minutes to complete the questionnaire. There were no difficulties understanding the language of the survey.

\section{Data analysis and psychometric scale properties}

All the analyses were conducted using IBM SPSS Statistics v. 26 and GraphPad Prism v.8 for the visualization of the results. The test-retest reliability of the questionnaire was examined by using Cronbach's alpha, and interclass correlation coefficient. The patients completed the questionnaire on two different occassions, so Cronbach's alpha was calculated for all two situations to determine internal validity.

Convergent and divergent construct validity were tested by using the spearman's correlation coeffiecnts for the 12-items of the oxford hip score and the WOMAC. 
Content validity was tested by examining the floor and ceiling effects. Floor effect represents the percentage of patients who had the lowest score (0), and ceiling effect is the percentage of those with the highest (100).

Correlation with WOMAC and OHS subscales were estimated to evaluate convergent validity of the MELLS questionnaire. If it was a valid instrument to measure hip/knee pain, its scores should have positive correlation with all the subscales from the questionnaire.

\section{Results}

All randomly selected patients filled out the questionnaires and the data collected were used in this study. None of the patients had any problem filling any part of the questionnaire. Hence, data of all 110 patients were used in this study.

\section{WOMAC \& OHS Questionnaires}

Before investigating the psychometric properties of MELLS, it is important to examine the instruments that are already being used in Arabic speaking countries for hip/knee pain assessment [10].

Reliability in the first assessment, which was calculated using Cronbach's alpha - was 0.95 for the pain subscale, 0.93 for the stiffness, and 0.98 for the physical function subscale. For the second testing, reliability was $0.96,0.95$, and 0.99 (pain, stiffness, and physical function, respectively).

In order to check content validity, floor and ceiling effects were examined. Five percent of the patients have recorded floor effect on pain subscale, $3 \%$ on stiffness subscale, and $3 \%$ on the physical function. On the other hand, $2 \%$ have recorded ceiling effect on pain subscale, $4 \%$ on stiffness subscale, and $0 \%$ on the physical function.

\section{Middle East Lower Limb Score (MELLS) Questionnaire}

To test the reliability of the instrument, Cronbach's alpha was obtained. For both assessments, an acceptable level of internal consistency was observed $-a_{1}=0.88, a_{2}=0.92$.

One percent of patients showed a ceiling effect in the first assessment with no floor effect. In the second assessment, $2 \%$ of them showed floor effect, and there was a recorded floor effect of $5 \%$. 
Table 1

Descriptive statistics of MELLS questionnaire

\begin{tabular}{|lllllllll|}
\hline \multicolumn{2}{|l}{ Assessment } & $\mathbf{N}^{1}$ & Min $^{2}$ & Max $^{3}$ & Mean & SD $^{4}$ & Floor effect & Ceiling effect \\
\hline MELLS & First & 110 & 0 & 100 & 55.52 & 12.01 & $0 \%$ & $1 \%$ \\
\hline & Second & 110 & 0 & 100 & 57.11 & 12.68 & $2 \%$ & $5 \%$ \\
\hline \multicolumn{2}{|l}{ Note: ${ }^{1}$ Sample size; ${ }^{2}$ Minimum; ${ }^{3}$ Maximum; ${ }^{4}$ Standard deviation; } \\
\hline
\end{tabular}

All of 110 patients that filled out the questionnaire in the first assessment, responded also to the second assessment after the initial evaluation.

Table 2

Mean, standard Deviation, Change, ICC between different assessments of each subscale

\begin{tabular}{|c|c|c|c|c|c|c|}
\hline \multirow[t]{3}{*}{ Questionnaires } & \multicolumn{4}{|c|}{ Scores } & \multirow[t]{3}{*}{ Change } & \multirow[t]{3}{*}{ ICC (95\% Cl) } \\
\hline & \multicolumn{2}{|c|}{$\begin{array}{l}\text { First } \\
\text { assessment }\end{array}$} & \multicolumn{2}{|c|}{$\begin{array}{l}\text { Second } \\
\text { assessment }\end{array}$} & & \\
\hline & Mean & SD & Mean & SD & & \\
\hline \multicolumn{7}{|l|}{ WOMAC } \\
\hline Pain & 54.22 & 15.80 & 63.27 & 18.75 & 9.05 & $\begin{array}{l}0.581(0.234- \\
0.760)\end{array}$ \\
\hline Stiffness & 54.38 & 16.74 & 63.44 & 18.40 & 9.06 & $\begin{array}{l}0.593(0.230- \\
0.772)\end{array}$ \\
\hline $\begin{array}{l}\text { Physical } \\
\text { Function }\end{array}$ & 54.31 & 16.25 & 62.85 & 18.10 & 8.54 & $\begin{array}{l}0.623(0.262- \\
0.793)\end{array}$ \\
\hline $\begin{array}{l}\text { Oxford Hip } \\
\text { Score }\end{array}$ & 54.54 & 25.26 & 59.32 & 16.34 & 4.78 & $\begin{array}{l}0.583(0.357- \\
0.730)\end{array}$ \\
\hline Total MELLS & 55.52 & 12.01 & 57.11 & 12.68 & 1.58 & $\begin{array}{l}0.866(0.780- \\
0.919)\end{array}$ \\
\hline Daily Activity & 53.78 & 10.23 & 56.22 & 9.65 & 2.44 & $\begin{array}{l}0.870(0.790- \\
0.950)\end{array}$ \\
\hline Pain & 56.44 & 15.54 & 59.01 & 11.34 & 2.57 & $\begin{array}{l}0.821(0.701- \\
0.941)\end{array}$ \\
\hline
\end{tabular}

Test-retest reliability was performed using Intra-class Correlation (ICC). The results (Table 2) indicated that OHS has a moderate intra-class correlation with $0.583(95 \% \mathrm{Cl} 0.357,0.730)$. WOMAC subscales also showed moderate intra-class correlations from 0.581 to 0.623 .

As shown in Fig. 1, all three questionnaires have resulted in similar patterns. However, WOMAC and OHS are visually proved to be more responsive to the changes of patient's conditions between each 
assessment.

\section{Validity of MELLS}

The results of Spearman's correlation in Table 3 indicate that MELLS subscales show moderate to high correlation with subscales of WOMAC. In the first assessment, daily activity of MELLS has the highest correlation with WOMAC Physical function $(r=0.73 ; p<0.01)$. Pain subscale of MELLS is also highly correlated with Pain of WOMAC $(r=0.72 ; p<0.01)$. These correlations have slightly decreased during the second assessment but remained fairly high and significant. In the second assessment, however, the correlation between MELLS subscales and OHS slightly increased.

Table 3

Construct validity of MELLS by calculating the Spearman's Correlation between MELLS, WOMAC and OHS

\begin{tabular}{|c|c|c|c|c|c|}
\hline & & \multicolumn{3}{|c|}{ WOMAC } & \multirow[t]{2}{*}{ OHS } \\
\hline & & Pain & Stiffness & Physical function & \\
\hline \multirow[t]{6}{*}{ MELLS } & \multicolumn{5}{|c|}{ First Assessment } \\
\hline & Daily Activity & $0.67 * \star$ & 0.70 ** & $0.73^{\star *}$ & 0.61 ** \\
\hline & Pain & $0.72^{\star *}$ & $0.69 * \star$ & $0.65^{\star *}$ & $0.65^{* *}$ \\
\hline & \multicolumn{5}{|c|}{ Second Assessment } \\
\hline & Daily Activity & $0.65^{\star \star}$ & $0.65^{\star \star}$ & $0.70 * \star$ & $0.62^{* *}$ \\
\hline & Pain & $0.70 \star *$ & $0.64 * \star$ & $0.60 * *$ & $0.66 * *$ \\
\hline
\end{tabular}

\section{Responsiveness}

Effects are often used to give meaning to change over time in terms of 'trivial' ( $E S<0.20)$, 'small' (ES $\geq$ $0.20<0.50$ ),'moderate' ( $E S \geq 0.50<0.80$ ) or 'large' ( $E S \geq 0.80)$ change. Cohen introduced this 'matched pairs' effect size, which was later renamed the standardised response mean (SRM) by Liang et al [11]. According to responsiveness test, MELLS in general show lower responsiveness than OHS and WOMAC. Pain subscale in WOMAC has a SRM of $0.482(0.382,0.582)$, while SRM of Pain in MELLS is 0.397 $(0.297,0.497)$. Both Stiffness and Physical function in WOMAC showed higher responsiveness than MELLS (Table 4). In comparison to MELLS, OHS also showed better responsiveness with SRM $=0.423$ $(0.361,0.485)$. This is important to note, however, that responsive change of all three questionnaires are very similar and the differences are not considerable. 
Table 4

Standardized Response Mean (SRM) for the WOMAC subscales and OHS and MELLS.

\begin{tabular}{|c|c|c|c|c|}
\hline Questionnaire & Subscales & SRM & $95 \% \mathrm{Cl}^{\prime}$ & \\
\hline \multirow[t]{3}{*}{ WOMAC } & Pain & 0.482 & 0.382 & 0.582 \\
\hline & Stiffness & 0.465 & 0.415 & 0.515 \\
\hline & Physical Function & 0.473 & 0.439 & 0.507 \\
\hline OHS & & 0.423 & 0.361 & 0.485 \\
\hline \multirow[t]{2}{*}{ MELLS } & Daily Activity & 0.384 & 0.374 & 0.394 \\
\hline & Pain & 0.397 & 0.297 & 0.497 \\
\hline
\end{tabular}

\section{Discussion}

Patient reported outcome (PRO) scores are helpful tools in clinical practice. They provide valuable input from the patients' perspective, helping the treating physician to assess the results of his or her treatment [12]. PRO scores are available in categories of upper or lower limb, or joint specific. The MELLS is a modification of the WOMAC Score and OHS, both of which are joint specific PRO's [12-13]. The authors found it necessary to assess the impact the cultural activities that might inversely affect current gold standard treatment guidelines. This will enable clinicians to justify certain treatments that divert from the recommended norms.

After careful modification of a current PRO's, the authors produced the MELLS to serve their population [14]. To further prove reliability and validity of the MELLS score, the psychometric properties were investigated and compared to other Lower Limb PRO's that are available in the current literature like the original WOMAC and OHS, and their Arabic counterparts. As seen from the results of this study, the MELLS compares well compared to the Arabic versions of WOMAC and OHS in terms of construct and conduct validity and internal consistency [15-17]. The numbers are closely relatable. The ICC of the MELLS and 0.866 compared to the Arabic WOMAC subscales (0.581-0.623) and OHS (0.583). The testretest reliability of the MELLS was 0.88 and 0.92 respectively. This compares to WOMAC which were $(0.96,0.95,0.95)[8,18]$.

Similar results were seen in the Moroccan version of the WOMAC score with a Cronbach's alpha for pain, stiffness, and physical function at $0.76,0.76$ and 0.9 respectively. The ICC for all three subscales were $0.77-0.89$ [12]. More recently in 2019, a Nepali version of the WOMAC was published with an ICC score > 0.75 in all domains. Cronbach's alpha in this study was $0.852,0.704,0.95$ for pain stiffness and physical function [13]. 
In brief, the MELLS serves as a utility in regions where the ADL's require frequent squatting, kneeling, bending and sitting cross-legged on the floor.

\section{Limitations}

The MELLS is a newly modified PRO score with this being the first study using the MELLS. However, a pilot study was conducted to address any outlaying burden or feasibility issues faced by the patient in completing this questionnaire. In addition, although it was tested for patients with knee and hip complaints, the authors did not include patients with ankle/foot complaints.

\section{Conclusion}

The need for region-specific PRO scores is on the rise, as surgeons around the globe face similar diseases but in patients from different backgrounds and cultures. This has led to discrepancies in outcomes according to different regions. The MELLS is a valid and reliable tool that can help clinicians in the region tailor their treatments more closely to suit patient's needs.

\section{Abbreviations}

MELLS - Middle East Lower Limb Score

WOMAC - Western Ontario and McMaster Universities Osteoarthritis Index

OHS - Oxford Hip Score

ICC - Inter Class Correlation

PRO - Patient Reported Outcome

\section{Declarations}

\section{Ethics approval}

- We obtained ethical approval

- We obtained the consent to publish from the participants

- Name of Ethical Committee: Ministry of Health, Kuwait, Research and publication office

- Committee Reference Number: 2019/1060

\section{Consent for publication}

Consent of participation and publish was obtained in written format from all participants.

\section{Availability of data and materials}


Not applicable

Competing interests: None

Funding: None

\section{Authors' contribution}

S. H: Concept, study design, data analysis, initial draft write-up.

F. A: Concept, study design, data analysis, final draft editing.

A. A: Data collection and literature review.

H. A: Data collection and analytics. $1^{\text {st }}$ draft editing.

B. A: Data collection and analytics. $1^{\text {st }}$ draft editing.

A. K: Study design, data analysis, final manuscript editing.

All authors read and approved the manuscript

\section{Acknowledgement}

The authors of this study wish to express their sincere gratitude to the authors of the original WOMAC score for allowing us to use their study as the base for Middle Eastern modification.

\section{References}

1. Bellamy N, Buchanan W.W, Goldsmith C.H, Campbell J, Stitt L.W (1988). Validation study of WOMAC: a health status instrument for measuring clinically important patient relevant outcomes to antirheumatic drug therapy in patients with osteoarthritis of the hip or knee. J Rheumatol; 15: 183340.

2. Bellamy N, Buchanan W.W, Goldsmith C.H, Campbell J, Stitt L (1988). Validation study of WOMAC: a health status instrument for measuring clinically important patient-relevant outcomes following total hip or knee arthroplasty in osteoarthritis. J Orthop Rheumatol, 1: 95- 108.

3. Bellamy N (1995). Outcome measurement in osteoarthritis clinical trials. J Rheumatol; 43Suppl: 4951.

4. Guillemin, F., Bombardier, C., \& Beaton, D. (1993). Cross-cultural adaptation of health-related quality of life measures: Literature review and proposed guidelines. Journal of Clinical Epidemiology, 46(12), 1417-1432.

5. Mathias, S. D., Fifer, S. K., \& Patrick, D. L. (1994). Rapid translation of quality of life measures for international clinical trials: avoiding errors in the minimalist approach. Quality of Life Research, 3(6), 
403-412.

6. Wild D., Grove A., Martin M., Eremenco, S., McElroy, S., Verjee-Lorenz, A., \& Erikson, P. (2005).

Principles of Good Practice for the Translation and Cultural Adaptation Process for Patient-Reported Outcomes (PRO) Measures: Report of the ISPOR Task Force for Translation and Cultural Adaptation. Value in Health, 8(2), 94-104.

7. Epstein, J., Santo, R. M., \& Guillemin, F. (2015). A review of guidelines for cross-cultural adaptation of questionnaires could not bring out a consensus. Journal of Clinical Epidemiology, 68(4), 435-441.

8. Guermazi M, Poiraudeau S, Yahia M, et al (2004). Translation, adaptation and validation of the Western Ontario and McMaster Universities osteoarthritis index (WOMAC) for an Arab population: the Sfax modified WOMAC. Osteoarthritis Cartilage; 12(6):459- doi:10.1016/j.joca.2004.02.006

9. Alghadir, A., Anwer, S., Iqbal, Z. A., \& Alsanawi, H. A. (2015). Cross-cultural adaptation, reliability and validity of the Arabic version of the reduced Western Ontario and McMaster Universities Osteoarthritis index in patients with knee osteoarthritis. Disability and Rehabilitation, 38(7), 689-694.

10. Liang MH, Fossel AH, Larson MG (1990). Comparisons of five health status instruments for orthopedic evaluation. Medical Care; 28(7):632-42.

11. Naal, F. D., Sieverding, M., Impellizzeri, F. M., von Knoch, F., Mannion, A. F., \& Leunig, M. (2009). Reliability and validity of the cross-culturally adapted German Oxford hip score. Clinical orthopaedics and related research, 467(4), 952-957.

12. Faik, A., Benbouazza, K., Amine, B., Maaroufi, H., Bahiri, R., Lazrak, N., ... Hajjaj-Hassouni, N. (2007). Translation and validation of Moroccan Western Ontario and Mc Master Universities (WOMAC) osteoarthritis index in knee osteoarthritis. Rheumatology International, 28(7), 677-683.

13. Nakarmi S, Haq SA, Vaidya B (2019). Translation, validation and cross-cultural adaptation of the Nepali version of WOMAC® LK 3.1. Int J Rheum Dis; 00:1-7.

14. Al-Samhan A, Al-Mutairi O, Al-Kudair A, Khaja A (2020) Validity and Reliability of the Cross-Cultural Arabic Adaptation of the Hip Disability and Osteoarthritis Outcome Score (HOOS). J Musculoskelet Disord Treat 6:077.

15. Aliaa Khaja, Owayed Al-Mutairi, Abdulaziz Al-Kudair, Awdhah Al-Samhan. (2020). Translation and Cross-Cultural Adaptation of the Harris Hip Score into Arabic. Global Journal of Medical Research, 20(1),31-39.

16. Khaja A, Al-Mutairi O, Al-Kudair A, Al-Samhan A (2020) Translation, adaptation and validation of the 12-item Oxford hip score into Arabic. Journal of Research and Practice on the Musculoskeletal System 5(1).

17. Alfadhel, S.A., Vennu, V., Alnahdi, A.H. et al (2018).Cross-cultural adaptation and validation of the Saudi Arabic version of the Knee Injury and Osteoarthritis Outcome Score (KOOS). Rheumatol 
Int 38, 1547-1555.

18. Alghadir, A.H., Al-Eisa, E.S. \& Anwer, S (2017). Cross-cultural adaptation and psychometric analysis of the Arabic version of the oxford knee score in adult male with knee osteoarthritis. BMC Musculoskelet Disord18,

\section{Figures}

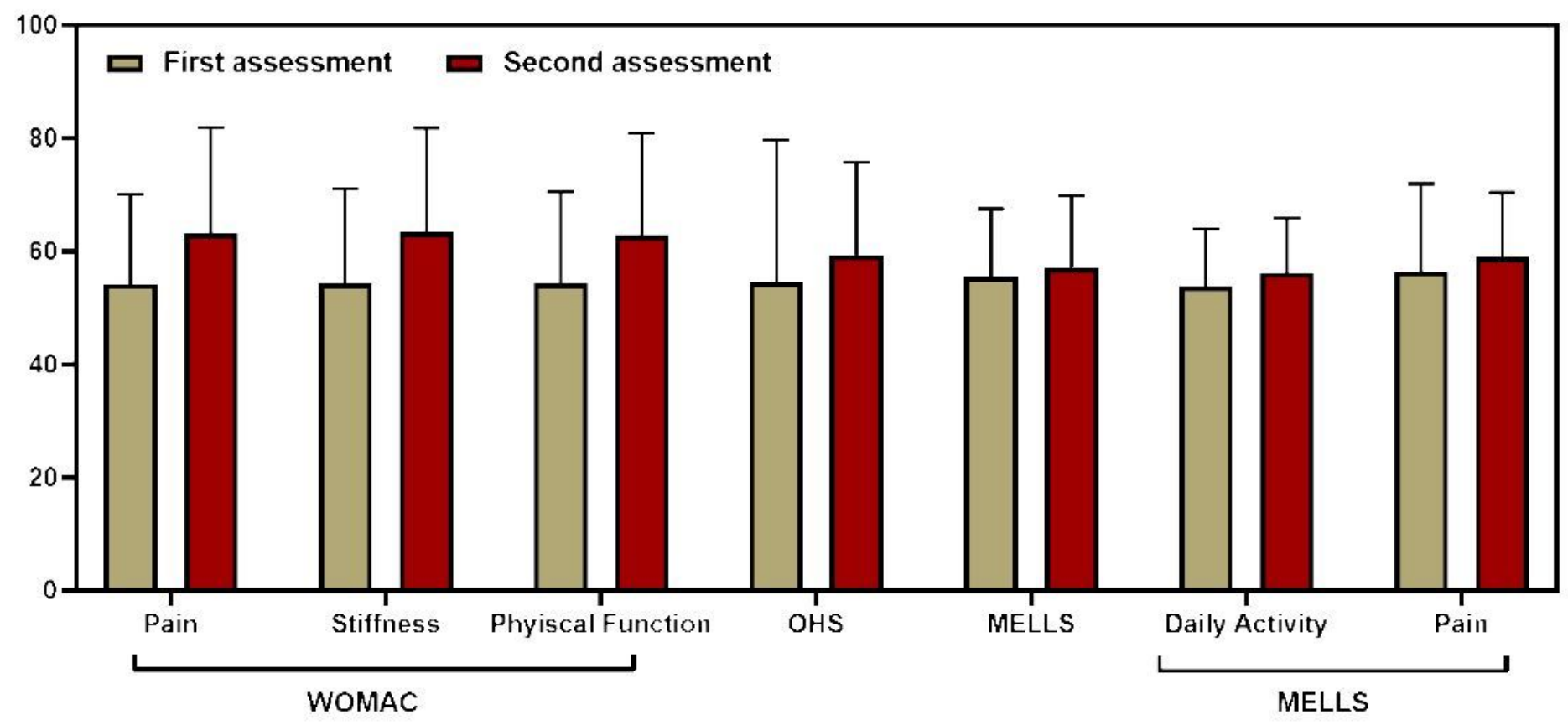

Figure 1

shows Mean score along with their standard deviations during 2 different assessments for MELLS, OHS and for WOMAC questionnaires. 